American Journal of Pharmaceutical Education 2016; 80 (7) Article 114.

\title{
RESEARCH
}

\section{An Observational Case Study of Near-peer Teaching in Medical and Pharmacy Experiential Training}

\author{
Bayan Sharif-Chan, PharmD, ${ }^{a}$ Dipti Tankala, PharmD, ${ }^{a}$ Christine Leong, PharmD, BScPhm, ${ }^{b}$ \\ Zubin Austin, PhD, MBA, MIS, BScPhm, ${ }^{a}$ Marisa Battistella, PharmD, BScPhm ${ }^{\mathrm{a}}$ \\ ${ }^{\text {a }}$ University of Toronto, Toronto, Ontario, Canada \\ ${ }^{\mathrm{b}}$ University of Manitoba, Winnipeg, Manitoba, Canada \\ Submitted June 28, 2015; accepted February 2, 2016; published September 25, 2016.
}

\begin{abstract}
Objective. To compare peer teaching in a medical and a pharmacy clinical teaching unit and to provide suggestions for future research in pharmacy near-peer teaching.

Methods. This exploratory observational study used principles of ethnographic methodology for data collection and analysis. Observations were collected in a large downtown teaching hospital. An average of 4-6 hours per day were spent observing a team of medical trainees from the Faculty (School) of Medicine in the general internal medicine (unit for two weeks, followed by a team of pharmacy trainees in an ambulatory hemodialysis (HD) unit for two weeks. Data was collected through field notes and informal interviews that were audiotaped and subsequently transcribed. Data was interpreted by the observer and reviewed weekly by two impartial pharmacists.

Results. Five major themes emerged: (1) influence of peer teaching hierarchy; (2) educational distance between peer learners and teachers; (3) effect of the clinical teaching unit size on peer learning; (4) trainees' perception of their teaching role in the clinical teaching unit; and (5) influence of daily schedule and workload on peer teaching. As opposed to pharmacy, a hierarchy and pyramidal structure of peer teaching was observed in medical experiential training. There appeared to be no effect of educational distance on near peer teaching; however, perception of teaching role and influence of daily schedule affected near-peer teaching.

Conclusion. Through initial comparisons of medical and pharmacy clinical teaching units, this study provides a reflection of elements that may be necessary to successfully implement near-peer teaching in pharmacy experiential training. Future studies in this area should assess learning outcomes and participant satisfaction, preceptor workload, and impact on patient care.
\end{abstract}

Keywords: peer teaching, near-peer teaching, layered learning

\section{INTRODUCTION}

Experiential peer teaching involves students teaching one or more fellow students. ${ }^{1}$ In particular, near-peer teaching (involving senior trainees, who are more advanced by at least one year, teaching junior trainees). ${ }^{2,3}$ Near-peer teaching is deeply rooted in the tradition of medical experiential training despite the paucity of evidence for its use. Although near-peer teaching is commonly used in medical experiential training, it is less often used in pharmacy experiential training. Consequently, there is an absence of literature on the implementation and benefits of near-peer teaching for pharmacy experiential training. ${ }^{4-7}$

Corresponding Author: Marisa Battistella, Toronto General Hosptial, 200 Elizabeth St., EB 214 - Pharmacy Department M5G 2C4, Toronto, Ontario, Canada. Tel: 416-340-4800, Ext. 3207. Fax: 416-340-3685. E-mail: marisa.battistella@uhn.ca
Benefits of near-peer teaching in the medical field include alleviating faculty teaching burden, providing role models for junior students, enhancing intrinsic motivation, and preparing physicians for their future role as educators. ${ }^{3}$ This may interest pharmacy educators facing the challenge of providing high-quality practice experiences for students as more Canadian pharmacy schools establish an entry level doctor of pharmacy (PharmD) program. ${ }^{5}$ The establishment of the entry level PharmD and concurrent legislative changes to enhance the scope of pharmacy practice in Canada demands research on the utility of near-peer teaching within pharmacy experiential education. The primary objective of this research was to compare and explore themes related to peer teaching in a medical clinical teaching unit and a pharmacy clinical teaching unit, based on qualitative observations. Secondly, the research aimed to provide suggestions for 


\section{American Journal of Pharmaceutical Education 2016; 80 (7) Article 114.}

future research in pharmacy experiential near-peer teaching.

\section{METHODS}

An exploratory observational study guided by ethnographic principles for data collection and analysis was employed. ${ }^{8}$ Ethnographic principles were used to describe the social interaction, behaviors, and perceptions of two clinical teaching units. ${ }^{9-12}$ All participants provided informed consent before observations began. The study was approved by the research ethics board at the teaching hospital. A final-year PharmD research student collected observations through field notes and informal interviews at a large downtown teaching hospital. The student received informal training from two pharmacists familiar with ethnographic principles. The PharmD research student spent 4-6 hours per day observing a team of medical trainees from the faculty (school) of medicine in the general internal medicine unit for two weeks, followed by a team of pharmacy trainees in an ambulatory hemodialysis (HD) unit for two weeks. In addition, 15minute personal interviews were conducted three times per week that were audiotaped and subsequently transcribed. Data were interpreted by the observer and reviewed weekly by two impartial pharmacists. Only one pharmacy team (HD unit) within the hospital used near-peer teaching, and as the HD unit at the hospital did not employ near-peer teaching for medical trainees, a clinical teaching unit from general internal medicine was selected. Thus, two different units were selected for observation for this study.

The pharmacy clinical teaching unit included one attending, a pharmacy resident, a PharmD student, and a bachelor of science in pharmacy (BScPhm) student. In Ontario, programs are transitioning from a $\mathrm{BScPhm}$ to a PharmD. Therefore, in this study, pharmacy trainees from both programs were included. The participants in the pharmacy clinical teaching unit each had varying levels of experience. The BScPhm program included four months of experiential training with a maximum of two months in the hospital. Prior to this study, only the BScPhm student had direct patient care experience in the community setting. The newly implemented PharmD program outlined nine practice experiences, each five weeks in length, and a minimum of 10 weeks in the hospital setting. The pharmacy resident had 34 weeks of hospital experience while the PharmD student had 24 weeks of hospital experience. None of the trainees had exposure to HD prior to participating in the clinical teaching unit. However, the PharmD student began the practice experience two weeks prior to the other trainees. The attending pharmacist had overseen groups of 2-4 pharmacy trainees with mixed levels of education over 10 years in the HD unit. The observed pharmacy clinical teaching unit managed 30 patients a day. Trainees provided direct patient care by performing a best possible medication history and developed a pharmaceutical care plan to identify and solve drug therapy problems, as well as monitor outcomes that were then discussed with the team. Additionally, the pharmacy trainees participated in informal peer teaching.

In medical experiential training, students progress from medical student to resident (usually three years in length) to attending practitioner. The medical clinical teaching unit included one attending, one third-year medical resident, three first-year medical residents, one fourthyear medical student, and two third-year medical students. With the exception of the third-year medical students, all trainees had prior general medicine practice experiences ranging from 5-8 weeks in various hospitals. ${ }^{13,14}$ The attending physician had more than 12 years of experience with near-peer teaching in general internal medicine. The observed medical clinical teaching unit handled approximately 15-20 patients per day. All trainees provided direct patient care by obtaining admission history, conducting a physical examination, and providing a diagnosis and a care plan for each patient. The medical residents were also responsible for teaching, assisting, and supervising medical students. The number of patients assigned to each trainee on a given day depended on overall team workload. The third-year medical students' level of responsibility was gradually increased.

\section{RESULTS}

The results are divided into five sections to better identify and describe the themes related to the structure and organization of peer teaching in both the pharmacy and medicine clinical teaching units: (1) educational distance and hierarchy; (2) dependence on the clinical teaching unit attending; (3) effect of clinical teaching unit size on peer learning; (4) perception of teaching roles; and (5) influence of schedule and workload on peer teaching.

In both clinical teaching units, a hierarchy was observed, and individuals with more clinical experience, positional authority, and knowledge were at the top. Additionally, the larger the educational distance, the higher in the hierarchy the individual was positioned. In both units, the attendings (both pharmacy and physician) were at the top of the hierarchy. In the pharmacy clinical teaching unit, the PharmD student and pharmacy resident had similar levels of experience and, therefore, had similar standings in the hierarchy. Initially, in the pharmacy clinical teaching unit, the PharmD student was higher in the hierarchy than the other trainees as the student started the practice experience two weeks prior to the other trainees 


\section{American Journal of Pharmaceutical Education 2016; 80 (7) Article 114.}

and assisted with training and orientation. By week 2, the resident functioned independently and it became unclear which individual the BScPhm student relied on more, as this student was comfortable consulting with either the PharmD student or pharmacy resident and approached them based on convenience. The attending was consulted for all major decisions regarding patient care, which included initiating and discontinuing medications. Unlike the pharmacy clinical teaching unit, the medical clinical teaching unit had a clear pyramidal structure. ${ }^{8,9}$ When asked, all trainees mentioned that they would always get help starting bottom up in the hierarchy if possible, rather than going directly to the attending.

The differences in medical and pharmacy hierarchy translated into varying levels of dependence on each attending. There was more dependence on the attending in the pharmacy unit compared to the medical unit. In cases where the pharmacy attending was not readily available, students were advised to rely on the interprofessional staff and discuss their recommendations with the medical fellows. There was no trainee equivalent to the third-year medical resident in the pharmacy model. Therefore, pharmacy trainees relied more heavily on one another for making patient care decisions. These decisions were then discussed with medical fellows. This reliance on one another was imposed by the absence of the attending. In the medical clinical teaching unit, however, from the beginning of the study the medical residents relied more on their near-peer teachers than their attending.

The pharmacy unit was much smaller than the medical unit with four and eight participants, respectively. The difference in size resulted in fewer opportunities for peer teaching in the pharmacy unit when absences occurred. In comparison, the medical unit provided ample opportunities for peer learning despite absences - a result of the number of trainees at different levels. The emphasis on peer learning was similar in both clinical teaching units; however, peer teaching in the pharmacy unit was further emphasized during the absence of the attending.

Throughout the study, the resident in the pharmacy clinical teaching unit was comfortable and familiar with the teaching role, and the $\mathrm{BScPhm}$ student identified as the learner. The PharmD student, however, was unsure of her role in the clinical teaching unit as it changed throughout the study. At first, the PharmD student held a higher position in the hierarchy and was teaching to a greater extent. This type of identity struggle was not observed among trainees in the medical clinical teaching unit. However, in both units, the satisfaction associated with peer learning was apparent as both the teacher and the learner discussed how they benefited from the interaction. Although peer teaching occurred in an informal setting for both clinical teaching units, there was a greater emphasis on formal structure peer teaching in the pharmacy unit. This formal peer teaching caused more anxiety for participating trainees.

Overall, both medicine and pharmacy trainees had to attend many required group activities such as therapeutic and patient discussions, interprofessional teaching rounds, and/or bedside rounds on a daily basis. However, they also had periods of time to work independently to complete day-to-day patient care activities, as well as participate in informal peer teaching sessions. Pharmacy and medical trainees had variable day-to-day schedules. Pharmacy trainees stated that the variability in daily schedules reduced the amount of time to complete daily patient care activities and incorporate informal peer teaching sessions. However, this sentiment changed towards the end of the study as trainees were better able to manage their schedules. Alternatively, the medical trainees reported that their schedule did not interfere with peer teaching or negatively affect daily patient care activities as they were informed prior to the practice experience of their variable daily schedules.

\section{DISCUSSION}

This study used ethnographic principles to explore themes present in near-peer teaching within a pharmacy and medical clinical teaching unit and themes found in previous near-peer teaching research. ${ }^{15-19}$ The necessity of hierarchy in near-peer teaching is inherent in the methodology: a senior trainee teaches a junior trainee. However, no evidence suggests that hierarchy adds any benefit to near-peer teaching. Benefits of peer teaching exist between peers regardless of educational distance, and an optimal educational distance between teacher and learner did not appear to exist. ${ }^{4,17}$ Although the benefits of hierarchy in near-peer teaching are unknown, it was apparent in the pharmacy clinical teaching unit that the lack of a clear hierarchy confused the PharmD student. The lack of pyramidal structure may have been a result of the minimal educational distance between the PharmD student and pharmacy resident or of the early start of the PharmD student at the HD unit. Despite the lack of clear hierarchy in the pharmacy clinical teaching unit, peer teaching still occurred. When implementing near-peer teaching, while it may be beneficial to outline the hierarchy within the clinical teaching unit to prevent confusion, it may not be necessary as there are typically only two levels of trainees: students and residents.

Compared to the pharmacy clinical teaching unit, a pyramidal structure of peer teaching was observed in the medical clinical teaching unit. The hierarchy may have translated into less anxiety and greater satisfaction 


\section{American Journal of Pharmaceutical Education 2016; 80 (7) Article 114.}

in near-peer teaching. Although this pyramidal structure has long existed in the medical unit, it may not be as clear in a pharmacy unit because most trainees are at the same or similar learning level; however, this is not a limitation, as the pharmacy trainees still benefited from peer teaching and expressed the benefits of learning from their peers. In fact, with increased pressure for more pharmacists to take on multiple students in their units, more students may become accustomed to and expect this type of peer learning environment.

Dependence on attendings was far greater in the pharmacy clinical teaching unit than the medical clinical teaching unit. This dependence on attendings can be reduced by encouraging trainees to adopt the teaching role. The trainees in medicine were accustomed to peer teaching because it was done in their previous practice experiences. But in pharmacy, many trainees were taking part in peer teaching for the first time. Pharmacy attendings need to be aware that students involved in peer teaching may endure an identity struggle, discovering their roles as teachers while learning themselves. Attendings can assist by periodically reviewing the expectations of the peer teaching sessions and creating opportunities for unobserved informal peer teaching sessions. Also, preceptors can provide students with feedback so students can improve their teaching skills. Further, pharmacy schools can teach students how to teach prior to their clinical placements.

The size of the clinical teaching unit may have affected the number of opportunities for peer teaching. The opportunities were fewer in the pharmacy clinical teaching unit and may have been related to the lack of participants. Regardless of the reduced number of participants in the pharmacy clinical teaching unit, near-peer teaching still seemed to occur. In comparison, the medical clinical teaching unit contained eight members, resulting in more opportunities for near-peer teaching. It is unclear whether the differences in near-peer teaching between the medical and pharmacy clinical teaching units were a result of the difference in clinical teaching unit size or of the varying experience levels or participant expectation of near-peer teaching. The critical mass of learners and teachers needed for effective peer teaching is not known. ${ }^{17}$

The introduction of near-peer teaching in the pharmacy clinical teaching unit did not appear to affect the workload of the participants. It is unclear whether the participants in the pharmacy clinical teaching unit were overwhelmed as a result of near-peer teaching or the inherent nature of the HD unit. In the medical clinical teaching unit, participants expected to teach throughout and were prepared for near-peer teaching, therefore peer informal teaching sessions were anticipated and incorporated into the daily schedule. This can be remedied by integrating teaching into the pharmacy curriculum prior to clinical practice and by informing students that they will be teaching other students prior to the practice experience.

Limitations in this study include observer and participant bias, differences in environment, short length of study, and limited generalizability. The observer may have influenced the themes as the participants were not blinded to the observer's identity. Because the student observer was also a pharmacy student, the participants of the pharmacy clinical teaching unit may have been more comfortable and open with their responses. Additionally, since the participants were not blinded to the observers' identity, they may have behaved differently. To reduce the risk of observer and participant bias, blinding the identity of the observer would be beneficial in future research.

Because of the inherent differences in the environments of the pharmacy and medical clinical teaching unit (in this case, an HD unit and general medicine unit, respectively), it can be argued that comparisons of nearpeer teaching cannot be made. However, the underlying principles of near-peer teaching among participants remain observable and unaffected by the differences in learning environments. The focus of this paper was to determine the interactions between the participants of the clinical teaching units and determine the themes present in near-peer teaching. Therefore, the difference in location of the two clinical teaching units is relevant but not problematic in delineating near-peer teaching themes.

Participants of each clinical teaching unit were observed for only two weeks, a length of time which may not have adequately captured all aspects of near-peer teaching. However, this study was an exploratory analysis to provide foundation for future research into near-peer teaching and, thus, a 2-week snap shot was appropriate. Finally, with only two teams observed, observations may have varied among individuals as a result of motivational and personality differences.

In the future, pharmacy-specific peer teaching studies may yield more conclusive results with a larger number of students in a variety of practice settings. Future researchers may want to assess learning outcomes, participant satisfaction, preceptor workload, impact on patient care, and the effectiveness of peer teaching strategies.

\section{CONCLUSION}

This study highlighted that although differences exist between medical and pharmacy clinical teaching units, trainees in both units supported and enjoyed near-peer teaching. Five themes of peer teaching emerged (hierarchy, educational distance, clinical teaching unit size, 


\section{American Journal of Pharmaceutical Education 2016; 80 (7) Article 114.}

perception of teaching role, and influence of daily schedule and workload) and should be considered by pharmacy preceptors who would like to implement peer teaching models into their practice. To improve near-peer teaching in clinical teaching units, preceptors may want to discuss expectations of near-peer teaching prior to the practice experience, clarify teaching hierarchy, ensure adequate time in the daily schedule for formal and informal peer teaching sessions, and provide feedback to students on their teaching style. Further research into the impact of near-peer teaching on learning outcomes, participant satisfaction, unit efficiency, and patient outcomes is necessary to incorporate near-peer teaching into pharmacy experiential education.

\section{REFERENCES}

1. Maudsley RF. The clinical teaching unit in transition. Can Med Assoc J. 1993;148(9):1564-1566.

2. Bulte C, Betts A, Garner K, Durning S. Student teaching: views of student near-peer teachers and learners. Med Teach. 2007;29(6):583-590. 3. Ten Cate O, Durning S. Peer teaching in medical education: twelve reasons to move from theory to practice. Med Teach. 2007; 29(6):591-599.

4. Ten Cate O, Durning S. Peer teaching in medical education: twelve reasons to move from theory to practice. Med Teach. 2007; 29(6):591-599.

5. Cisneros RM, Salisbury-Glennon JD, Anderson-Harper HM. Status of problem-based learning research in pharmacy education: a call for future research. Am J Pharm Educ. 2002;66(1):19-26.

6. Leong C, Battistella M, Austin Z. Implementation of a near-peer teaching model in pharmacy education: experiences and challenges. Can J Hosp Pharm. 2012;65(5):394-398.

7. Lindblad AJ, Howorko JM, Cashin RP, Ehlers CJ, Cox CE.

Development and evaluation of a student pharmacist clinical teaching unit utilizing peer-assisted learning. Can J Hosp Pharm. 2011; 64(6):446-450.

8. Reeves S, Kuper A, Hodges BD. Qualitative research methodologies: ethnography. BMJ. 2008;337:512-514.

9. Leung WC. Why is evidence from ethnographic and discourse research needed in medical education: the case of problem-based learning. Med Teach. 2002;24(2):169-172.

10. Atkinson P, Pugsley L. Making sense of ethnography and medical education. Med Educ. 2005;39(2):228-234.

11. Goodson L, Vassar M. An overview of ethnography in healthcare and medical education research. $J$ Educ Eval Health Prof. 2011;8:4.

12. Walton JM, Steinert Y. Patterns of interaction during rounds: implications for work-based learning. Med Educ. 2010;44(6): 550-558.

13. General internal medicine clinical teaching unit - senior resident. University of Toronto Department of Medicine; 2013. http://www. deptmedicine.utoronto.ca/Assets/DeptMed+Digital+Assets/ Core + Internal + Medicine + Files/clinical teaching unitsrobjectives.pdf. 14. The CanMEDS framework. Royal College of Physicians and Surgeons of Canada. 2011. http://www.royalcollege.ca/rcsite/ canmeds/framework/teaching-assessing-canmeds-framework-e 15. Lempp H, Seale C. The hidden curriculum in undergraduate medical education: qualitative study of medical students' perceptions of teaching. BMJ. 2004;329(7469):770-773.

16. Mahood SC. Medical education: beware the hidden curriculum. Can Fam Physician. 2011;57(9):983-985.

17. Vaughn LM, Baker RC. Psychological size and distance: emphasizing the interpersonal relationship as a pathway to optimal teaching and learning conditions. Med Educ. 2004;38(10):10531060 .

18. Ten Cate O, Durning S. Dimensions of psychology of peer teaching in medical education. Med Teach. 2007;29(6):546-552. 19. Leong C, Battistella M, Austin Z. Implementation of a near-peer teaching model in pharmacy education: experiences and challenges. Can J Hosp Pharm.2012;65(5):394-398. 